\title{
TIPOLOGIA DE POLÍTICAS PÚBLICAS COMO INSTRU- MENTO DE GESTÃO, EXECUÇÃO, COORDENAÇÃO E AVALIAÇÃO DO DESENVOLVIMENTO REGIONAL: UMA APLICAÇÃO PARA O RIO GRANDE DO SUL
}

\author{
Mario Jaime Gomes de Lima* \\ Osmar Tomaz de Souza**
}

\begin{abstract}
Resumo
O objetivo do artigo é analisar se a construção de Políticas Públicas de Desenvolvimento Regional no Estado do Rio Grande do Sul, geradas no âmbito dos Conselhos Regionais de Desenvolvimento - COREDE dão condições para o desenvolvimento regional como propõe a Constituição Estadual, juntamente com os argumentos de institucionalização de regiões, governança, responsabilização e clareza da restrição orçamentária. A análise se dá pela aplicação da tipologia de Políticas Públicas de Desenvolvimento Regional proposta por Figueiredo (2009) no âmbito de 03 (três) Regiões Funcionais de Planejamento (RFP) do Estado do Rio Grande do Sul, em seus respectivos Conselhos Regionais de Desenvolvimento (COREDE's): Hortênsias, Serra e Campos de Cima da Serra (RFP 3); Campanha e Fronteira Oeste (RFP 6) e; Alto da Serra do Botucaraí, Médio Alto Uruguai, Nordeste, Norte, Produção e Rio da Várzea (RFP 9).
\end{abstract}

Palavras-chave: Políticas Públicas. Desenvolvimento Regional. Regionalização Administrativa.

\footnotetext{
* Economista, Mestre em Economia do Desenvolvimento (PPGE/PUCRS).E-mail: mariojgl@gmail.com

** Doutor em Economia, Professor e Pesquisador do Programa de Pós-Graduação em Economia da Pontifícia Universidade Católica do Rio Grande do Sul - PUCRS (PPGE/PUCRS).E-mail: osmar.souza@pucrs.br
} 


\section{Introdução}

1 Para Evans (1989), sinergia são relações entre governos e grupos de cidadãos engajados que se reforçam mutuamente.
As Políticas Públicas orientam as ações da administração pública, com a utilização de métodos e normas para estabelecer a sinergia ${ }^{1}$ entre administração pública e sociedade, entre Estado e atores sociais. A partir da sua elaboração e implementação, as Políticas Públicas demonstram a execução do poder político, que envolve a distribuição e redistribuição de poder, os processos de decisão e seus conflitos, além da repartição de custos e recursos para oferta de bens e serviços públicos (TEIXEIRA, 2002). De acordo com o aspecto econômico em escala regional, as Políticas Públicas tornam-se Políticas Públicas de Desenvolvimento Regional, as quais buscam propiciar o desenvolvimento de ações de equidade inter-regional, considerando a região como um território com escala e massa crítica de recursos suscetíveis, concebidas e implementadas a partir de um quadro estratégico de prospecção com base em um determinado território, com níveis desiguais de participação dos atores regionais e locais (FIGUEIREDO, 2009).

Por meio da sistematização das Políticas Públicas de Desenvolvimento Regional, segundo uma tipologia das falhas de mercado justificadoras de sua existência, os paradigmas da economia regional podem constituir um referencial de análise. De forma genérica, a economia regional e dos territórios têm evoluído no sentido de atribuir importância relativa diferenciada a diferentes falhas de mercado e pelo quanto essa evolução poderá conduzir à desejada sistematização das Políticas Públicas de Desenvolvimento Regional (FIGUEIREDO, 2009).

Com base na abordagem metodológica proposta por Figueiredo (2009), em que é construída uma tipologia de Políticas Públicas de Desenvolvimento Regional a partir das falhas de mercado, torna-se possível realizar a gestão, execução, coordenação e avaliação de Políticas Públicas de Desenvolvimento Regional.

Portanto, o objetivo do artigo é analisar se a construção de Políticas Públicas de Desenvolvimento Regional no Estado do Rio Grande do Sul, geradas no âmbito dos COREDE's dão condições para o desenvolvimento regional como propõe a Constituição Estadual, juntamente com os argumentos de institucionalização de regiões, governança, responsabilização e clareza da restrição orçamentária. A análise se dará pela a aplicação da tipologia de Políticas Públicas de Desenvolvimento Regional proposta por Figueiredo (2009) no âmbito de 03 (três) Regiões Funcionais de 
Planejamento (RFP) do Estado do Rio Grande do Sul (3, 6 e 9), em seus respectivos Conselhos Regionais de Desenvolvimento (COREDE's): Hortênsias, Serra e Campos de Cima da Serra (RFP 3); Campanha e Fronteira Oeste (RFP 6) e; Alto da Serra do Botucaraí, Médio Alto Uruguai, Nordeste, Norte, Produção e Rio da Várzea (RFP 9).

\section{Políticas Públicas de Desenvolvimento Regional: um referencial teórico}

\section{As Politicas Públicas}

As Políticas Públicas dentro do estudo da política analisam o governo à luz de grandes questões públicas (MEAD, 1995), produzindo efeitos específicos (LYNN; GOULD, 1980), agindo de forma direta ou através de delegação,influenciando a vida dos cidadãos (PETERS, 1986), como também dos governos que escolhem ou não fazer (DYE, 1984), imprimindo questões como "quem ganha o que?", "por quê?" e "que diferença faz?"(SOUZA, 2006).

Considera-se que a área de Políticas Públicas possui, como fundadores, Laswell, Simon, Lindblom e Eastone. Laswell (1936) conciliou o conhecimento científico / acadêmico e a produção empírica dos governos; Simon (1957) inseriu o conceito de "racionalidade limitada dos decisores públicos" (policy makers); Lindblom (1959) discutiu a ênfase no racionalismo de Laswell e Simon, propondo a incorporação de outras variáveis para formular e analisar as Políticas Públicas; e Eastone (1965) contribuiu ao definir a Políticas Públicas como um sistema, formatado por uma relação entre a formulação, os resultados e o ambiente.

De acordo com uma observação teórica - conceitual, as Políticas Públicas estão dentro de campos multidisciplinares orientados a explicar a natureza das Políticas Públicas e seus processos, na busca da construção de uma teoria geral, que tenha como objetivo, sintetizar teorias de diferentes ciências sociais, como as da ciência econômica (SOUZA, 2006).

No aspecto econômico ${ }^{2}$, as Políticas Públicas são diretamente associadas às falhas de mercado ${ }^{3}$, em que a administração pública busca intervir com o intuito de proporcionar ótimos sociais que não podem ser maximizados por agentes privados (FIGUEIREDO, 2009).

Logo, de acordo com o aspecto econômico em escala regional, as Políticas Públicas tornam-se Políticas Públicas
2 Segundo Scarth (1988), os economistas keynesianos consideram as Políticas Públicas de natureza estatal associadas essencialmente às falhas de mercado. É considerando essa ótica que as Políticas Públicas serão avaliadas no presente artigo e, conforme essa avaliação, será feita a tipologia de Políticas Públicas de Desenvolvimento Regional na sequência.

3 Falhas de mercado como a existência de bens públicos; falha de competição que se reflete na existência de mercados de monopólios naturais; externalidades positivas e negativas; mercados incompletos; as falhas de informação e a ocorrência de desemprego e a inflação (DE LIMA, 2006). 
de Desenvolvimento Regional, em que buscam propiciar o desenvolvimento de ações de equidade inter-regional, considerando a região como um território com escala e massa crítica de recursos suscetíveis, concebidas e implementadas a partir de um quadro estratégico de prospecção com base em um determinado território, com níveis desiguais de participação dos atores regionais e locais (FIGUEIREDO, 2009).

Com a Crise do Estado, que teve início na década de 1970, e eclosão no início da década de 1980, os pensadores e formuladores de Políticas Públicas no Brasil e no mundo, repensaram o modelo até então adotado na elaboração e execução de Políticas Públicas.

As Políticas Públicas, que antes eram geradas por meio de um planejamento estatal centralizado, iniciam uma mudança a partir de uma Reforma do Estado, em especial uma Reforma Administrativa do Setor Público, com base na descentralização político-administrativa e na desconcentração, resultando assim numa Regionalização Administrativa (FIGUEIREDO, 2009). O estabelecimento da Regionalização Administrativa, a partir do território ultrapassa o envolvimento de uma simples aceitação de divisão regional, partindo de argumentos peculiares de governo, podendo ser considerada como uma regionalização do planejamento, uma vez que tem origem na aplicação de critérios político-administrativos, que são instrumentalizados na atividade de planejamento.

Diante disso, a Regionalização Administrativa também é determinada por aspectos políticos, sociais e econômicos como a institucionalização de regiões, estágios de governança, responsabilização e clareza da restrição orçamentária.

A institucionalização de regiões, parte de critérios para definir regiões, no que se refere à abrangência territorial, em que privilegie sua funcionalidade, no que diz respeito à articulação de atores sociais, políticos e econômicos, não sofrendo pela passividade de ações concebidas e implementadas "de fora para dentro" e "de cima para baixo".

A governança se dá quando os atores regionais e locais, conjugadamente, desempenham ações de avaliação de problemas pertinentes às suas regiões ou locais, objetivando observar os problemas de uma melhor forma em comparação com atores nacionais ou supra-nacionais. 
A responsabilização (ou accountability) explica aspectos afirmando que os governos são responsáveis junto aos cidadãos, devendo realizar a transparência e prestar contas de seus atos; assim como salientar o direito dos cidadãos controlarem as ações da administração pública.

A clareza da restrição orçamentária possibilita informar o comportamento do mercado diante das diversas políticas de arrecadação ou despesas, podendo fazer os governos escolherem aquelas políticas que possibilitam resultados ótimos, além de preverem alterações futuras em Políticas Públicas, que serão geradas e impactadas pelo comportamento do mercado.

O Estado do Rio Grande do Sul (RS), na primeira metade da década de 1990, iniciou uma tentativa de Regionalização Administrativa por meio da implementação dos Conselhos Regionais de Desenvolvimento (COREDE's), com base na Constituição Estadual, em especial no que se refere ao desenvolvimento regional, expressa nos artigos 166 a 170, que tratam da criação de um órgão específico para o planejamento do desenvolvimento regional e de um instrumento de participação popular no processo de decisão de Políticas Públicas de Desenvolvimento Regional.

A implementação dos COREDE's, buscava o rompimento com o modelo tradicional centralizado de gestão pública, como resposta às transformações que ocorreram a partir da década de 1980 no Brasil e no mundo (KRUTZMANN; MASSUQUETTI, 2008).

Assim, a partir da aplicação de uma tipologia de Políticas Públicas de Desenvolvimento Regional proposta por Figueiredo (2009), poderá observar-se se a construção de Políticas Públicas de Desenvolvimento Regional no âmbito dos COREDE's, no período 2003-2010, dão condições para o desenvolvimento regional, como propõe a Constituição Estadual.

\section{A Tipologia das Políticas Públicas de Desenvolvimento Regional:Instrumento de Gestão, Execução, Coordenação e Avaliação de Políticas Públicas de Desenvolvimento Regional}

Com uma visão multivariada da evolução das Políticas Públicas de Desenvolvimento Regional de Portugal, Figueiredo (2009, p. 681) colabora ao fornecer: 
[...] um referencial de análise que ajude a sistematizar e a construir uma apreciação crítica fundamentada das políticas de iniciativa central, regional e local direta ou indiretamente associáveis ao tema do desenvolvimento. A abordagem do quadro diversificado e evolutivo das Políticas Públicas de Desenvolvimento Regional é realizada tendo sempre presente o sistema de planejamento que concebe, executa, coordena, acompanha e avalia tais políticas.

Como as Políticas Públicas são essencialmente associadas à existência de falhas de mercado (intervindo de forma a gerar ótimos sociais que não são atingidos pelo somatório de decisões de atores privados), a utilização de uma tipologia de Políticas Públicas de Desenvolvimento Regional, tendo como referência as falhas de mercado, torna possível analisar se as Políticas Públicas de Desenvolvimento Regional dariam condições para propiciar o desenvolvimento regional, ao satisfazer uma evolução sistemática dos tipos de políticas.

Dentro de um quadro institucional, as Políticas Públicas de Desenvolvimento Regional se encaminham, de forma exclusiva, para o domínio de Políticas Públicas, independente do âmbito da administração pública, agindo essencialmente nas falhas de mercado para atingir ótimos sociais.

As Políticas Públicas de Desenvolvimento Regional são geradas a partir das falhas de mercado existentes nas regiões, com tendências normativas, a partir de um nível social ou politicamente indesejável, com sucessivos desequilíbrios da renda per capita ou entre o distinto comportamento de desenvolvimento das regiões.

Diante disso, Figueiredo (2009, p. 685) sistematiza a tipologia das Políticas Públicas de Desenvolvimento Regional da seguinte forma: 
Quadro 1 - Tipologia das Políticas Públicas de Desenvolvimento Regio-

nal, falhas de mercado e paradigmas de referência

\begin{tabular}{|c|c|c|}
\hline $\begin{array}{l}\text { Tipologia de Políticas } \\
\text { Públicas de Desenvolvi- } \\
\text { mento Regional }\end{array}$ & $\begin{array}{l}\text { Objetivos e natureza } \\
\text { do papel supletivo em } \\
\text { relação ao mercado }\end{array}$ & Paradigma - Referência \\
\hline $\begin{array}{l}\text { Politicas de incentivos } \\
\text { à mobilidade de fatores, } \\
\text { particularmente de capi- } \\
\text { tal de organização }\end{array}$ & $\begin{array}{l}\text { Superar efeitos da } \\
\text { segmentação de merca- } \\
\text { dos } \\
\text { Remover obstáculos } \\
\text { à livre circulação de } \\
\text { fatores }\end{array}$ & $\begin{array}{l}\text { Princípio do nivelamento } \\
\text { tendencial dos mercados e da } \\
\text { mobilidade reequilibradora } \\
\text { dos fatores em contexto de } \\
\text { espaço homogêneo } \\
\text { Abundância / escassez rela- } \\
\text { tivas dos fatores comandam } \\
\text { a sua remuneração relativa } \\
\text { e, consequentemente, a sua } \\
\text { mobilidade }\end{array}$ \\
\hline $\begin{array}{l}\text { Políticas de promoção } \\
\text { de bem-estar material e } \\
\text { imaterial de territórios }\end{array}$ & $\begin{array}{l}\text { Discriminação social } \\
\text { positiva de territórios } \\
\text { regulando e corrigindo } \\
\text { insuficiências e lacunas } \\
\text { de mercado em matéria } \\
\text { de bem-estar material e } \\
\text { imaterial }\end{array}$ & $\begin{array}{l}\text { Estado - Providência ou } \\
\text { Estado - Social para os } \\
\text { territórios } \\
\text { A equidade como valor } \\
\text { intrínseco do desenvolvimen- } \\
\text { to regional }\end{array}$ \\
\hline $\begin{array}{l}\text { Políticas de mobilização } \\
\text { e valorização de capital } \\
\text { endógeno }\end{array}$ & $\begin{array}{l}\text { Remover círculos viciosos } \\
\text { e bloqueios à mobilização } \\
\text { e valorização de recursos } \\
\text { Viabilização de externali- } \\
\text { dades de procura }\end{array}$ & $\begin{array}{l}\text { Desenvolvimento sustentado } \\
\text { e abordagem bottom-up } \\
\text { "Desenvolvimento Endógeno" }\end{array}$ \\
\hline $\begin{array}{l}\text { Políticas de promoção e } \\
\text { valorização de externali- } \\
\text { dades da competitividade } \\
\text { empresarial }\end{array}$ & $\begin{array}{l}\text { Intervir no ambiente } \\
\text { externo da competitivi- } \\
\text { dade das empresas }\end{array}$ & $\begin{array}{l}\text { Economia de aglomeração e } \\
\text { conhecimento implícito } \\
\text { O meio (inovador) como } \\
\text { ativo econômico intangível } \\
\text { Modelos de crescimento } \\
\text { endógeno e externalidades }\end{array}$ \\
\hline $\begin{array}{l}\text { Políticas de promoção } \\
\text { de competitividade } \\
\text { territorial }\end{array}$ & $\begin{array}{l}\text { Dotação de infraestru- } \\
\text { turas produtivas } \\
\text { Atratividade e conecti- } \\
\text { vidade } \\
\text { Valorização das massas } \\
\text { críticas de aglomeração } \\
\text { urbana }\end{array}$ & $\begin{array}{l}\text { Modelo de vantagens compe- } \\
\text { titivas ajustado ao território }\end{array}$ \\
\hline $\begin{array}{l}\text { Políticas territoriais de } \\
\text { aplicação do conceito de } \\
\text { estratégias de eficiência } \\
\text { coletiva }\end{array}$ & $\begin{array}{l}\text { Ação mista de interven- } \\
\text { ção no ambiente externo } \\
\text { da competitividade das } \\
\text { empresas e das econo- } \\
\text { mias de rede }\end{array}$ & $\begin{array}{l}\text { Modelos de competitividade } \\
\text { sistêmica e teoria das redes }\end{array}$ \\
\hline $\begin{array}{l}\text { Políticas de robusteci- } \\
\text { mento da espessura } \\
\text { institucional }\end{array}$ & $\begin{array}{l}\text { Proporcionar supleti- } \\
\text { vamente capacidade de } \\
\text { iniciativa }\end{array}$ & $\begin{array}{l}\text { Regiões aprendentes (learning } \\
\text { regions) }\end{array}$ \\
\hline
\end{tabular}

Fonte: Figueiredo (2009) 
Para Figueiredo (2009, p. 686), é "comum a arquitetura de Políticas Públicas de Desenvolvimento Regional num sistema de planejamento concreto combinar de modo diverso os tipos de políticas, atribuindo ou não a algum dos tipos considerados o estatuto de política estruturante".

Assim, as políticas de mobilidade dos fatores representam a base das Políticas Públicas de Desenvolvimento Regional, a partir da regulação e correção do modelo neoclássico de crescimento regional, este que, baseado em um espaço homogêneo, considera a transferência de fatores de produção abundantes de uma região para outra que apresenta uma escassez relativa desses fatores.

Essas políticas agem para diminuir os custos do capital e do investimento, incentivando a transferência de capital para regiões com menor escassez relativa de fatores, por meio de incentivos fiscais ou financiamentos de longo prazo, influenciando o custo do capital.

Cursos para capacitação de gestores municipais, programas de eletrificação rural e de distritos industriais, assim como políticas de incentivos locais ou regionais de atração de empreendimentos são exemplos desses tipos de Políticas Públicas de Desenvolvimento Regional.

Políticas de promoção do bem-estar territorial consistem em políticas sociais voltadas a regiões com carências e necessidades básicas, que visam reduzir as assimetrias existentes entre as regiões.

Essas políticas são construídas com base no conceito de equidade, dirigidas do crescimento para o desenvolvimento, de forma normativa, não sendo necessariamente ligadas ao conceito de "justiça territorial".

As políticas de transferências de recursos para regiões menos favorecidas são um exemplo deste tipo de Políticas Públicas de Desenvolvimento Regional, assim como a manutenção e conservação de espaços escolares para a conservação e recuperação no estado de depreciação natural dos prédios, segurança e comunidade escolar e adaptação dos espaços para portadores de necessidades especiais.

As ações voltadas para não mobilidade de capital são encontradas nas políticas de mobilização e valorização do capital endógeno nas regiões, respeitando as condições de vantagens comparativas e a valorização externa de recursos endógenos a serem valorizados e aqueles mobilizados, em que a importação 
pode ser aplicada a toda economia, menos ao processo de desenvolvimento.

São políticas que agem no campo institucional, buscando a integração do processo de desenvolvimento, a partir de uma lógica de integração com a participação democrática da população, juntamente das instituições locais, sendo agentes da promoção e do resultado do planejamento, gestão e construção do planejamento.

Políticas preocupadas com recuperação de áreas degradadas, projetos integrados de desenvolvimento sustentável e apoio ao empreendedorismo são exemplos de políticas de mobilização e valorização do capital endógeno.

Uma nova concepção de Políticas Públicas, fundamentada e organizada a partir do conceito de impactos externos (externalidades) nos problemas territoriais e regionais, são as políticas voltadas à promoção e valorização de externalidades da competitividade empresarial.

Essas políticas são capazes de promover e influenciar o ambiente externo das empresas - condicionados a partir de diversificadas formas de articulação entre as empresas e as regiões - e da sua competitividade com a dimensão territorial apresentando-se de forma integrada, sendo uma área de atuação das externalidades das empresas.

Essas políticas inicialmente eram voltadas à infraestrutura produtiva, influenciadas no ambiente externo da capacidade empresarial. Em seguida, ligam-se à adoção da região como fonte de geração, aprendizagem e acumulação de conhecimento empresarial, encaminhando, desta forma, a função das políticas como instrumentos de valorização da região e a atuação como mantenedora da cultura empresarial da região.

São exemplos deste tipo de Política Pública de Desenvolvimento Regional: ações voltadas à valorização de clusters regionais sejam eles direcionados à inovação, tecnologia e logística, como polos de inovação tecnológica e fomento à pesquisa e formação de recursos humanos.

As políticas de promoção da competitividade territorial, tendo como base o conceito de que um território competitivo tem, como princípio, a combinação de recursos, dentre eles o conhecimento e a organização, adquirem um perfil com particularidades em comparação com outros territórios em um longo e determinado intervalo temporal, que sustente estratégias de desenvolvimento (FIGUEIREDO, 2009). 
Essas políticas são voltadas às organizações urbanas e regionais, direcionadas ao conceito de cidades ou regiões competitivas, além de cumprirem com a função de estruturar e fortalecer as identidades culturais e ou de lazer, com atratividade internacional, com base na estruturação dos atributos vocacionais das regiões.

As políticas territoriais baseadas na aplicação do conceito de estratégias de eficiência coletiva tratam do modelo de competitividade sistêmica de empresas, em combinação com os problemas de economias de rede, em relação ao distanciamento regional de eficiência empresarial coletiva.

Tais políticas têm sido ampliadas a partir de novas tipologias de desenvolvimento regional, especialmente aquelas relacionadas à dinâmica da valorização dos recursos endógenos, em regiões com menor número de empresas, considerando ainda a dinâmica da competitividade urbana.

Os tipos dessas Políticas Públicas de Desenvolvimento Regional são voltados a programas de ação, visando a inovação, a qualificação ou a modernização de um conjunto de empresas, que empreguem de forma estruturada a cooperação entre empresas e outros atores pertencentes ao território. A qualificação de trabalhadores e a construção de programas para a inserção de jovens no mercado de trabalho em determinada região são exemplos dessa política.

Já as políticas de robustecimento da espessura institucional das regiões partem do pressuposto de que a coesão social e econômica é entendida como o nível social politicamente tolerável de desequilíbrios entre o desenvolvimento de diferentes regiões, sendo que a competitividade econômica e essa coesão não podem ocorrer de forma desassociada.

Desta forma, combinações entre a eficiência, coesão e direitos passam a formar um abrangente campo de preocupação para as políticas, em relação ao impacto nas regiões e no desenvolvimento regional (FIGUEIREDO, 2009). O Esquema de Mayes (MAYES, 1995 apud FIGUEIREDO, 2009) ajuda a materializar tal compreensão: 
Figura 1 - Esquema de David Mayes: competitividade, coesão e direitos sociais

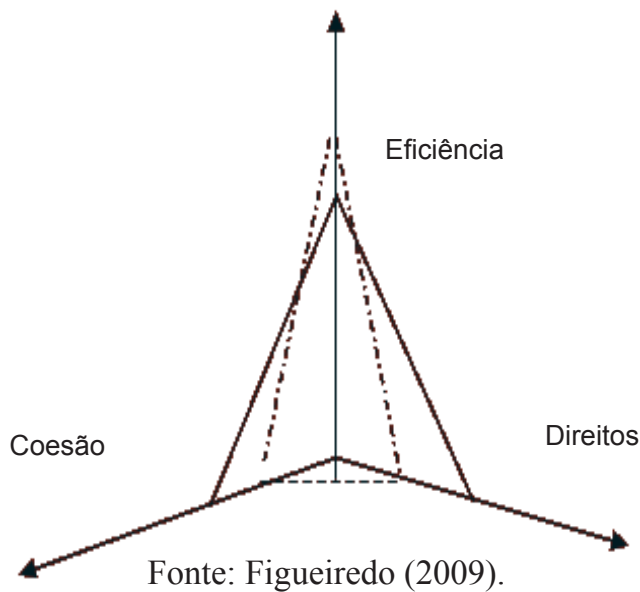

De acordo com essa abordagem, a competitividade das regiões evolui com tendência a formar um produto resultante da combinação sustentada dos 03 (três) eixos apresentados na Figura 1 , significando que no processo de longo prazo, perfazendo uma dinâmica, os baixos níveis de coesão e direitos, de forma sistêmica e não assegurados, tendem a arruinar os resultados em relação ao eixo de eficiência.

Para Figueiredo (2009, p. 696), a competitividade das regiões:

[...] depende assim da própria qualidade da "governança" territorial e dos níveis de capital social e de confiança existentes numa dada região ou território. Por esta via, a capacidade de D. Mayes acaba por contribuir para a durabilidade da diferenciação competitiva dos mesmos. Por outro lado, essa capacidade é acumulável mediante processos de aprendizagens social e institucional. Daí pode falar-se de "learning regions", ou seja, de regiões que acumulam experiência, conhecimento, saber-fazer para a diferenciação competitiva, seja ela a da inovação tecnológica, a do lazer, da valorização dos recursos naturais e das paisagens, etc.

Assim, as Políticas Públicas de Desenvolvimento Regional realizam apoio direto à conjuntura institucional das regiões, com suas diversidades, sustentação, com seus referenciais técnicos, elegendo e formando redes de cooperação entre as instituições como objetivo dessas Políticas Públicas, com administrações públicas, sejam elas centrais ou regionais, com elevada eficiência e 
competência para promover a sustentabilidade do desenvolvimento estratégico e organizacional das instituições.

Exemplos desse tipo de política são as organizações específicas para construção do planejamento de Políticas Públicas, visando o desenvolvimento regional com a participação da população de uma determinada região, além de ações que visem a participação da sociedade nas decisões da comunidade de uma região.

O Quadro 1 pode ser observado de forma evolutiva, mas também como uma disposição de Políticas Públicas de Desenvolvimento Regional, que não se estabelecem necessariamente de forma temporal, podendo ser utilizado para uma observação de complementaridade, sendo possível ocorrer em um planejamento real a combinação de diversos tipos de Políticas Públicas de Desenvolvimento Regional.

\section{Desenvolvimento Regional no Estado do RS: análise a partir da aplicação de uma tipologia de Políticas Públicas de Desenvolvimento Regional}

Noperíodo2003-2010,osCOREDE’sdasRegiõesFuncionais de Planejamento 03, 06 e 09 (Composição dos COREDE's no Anexo A), atendendo os critérios de institucionalização de regiões, estágios de governança, responsabilização e clareza da restrição orçamentária por meio da Consulta Popular, tiveram a seguinte distribuição orçamentária em valores presentes:

Tabela 1 - Distribuição Orçamentária da Consulta Popular nos COREDE's das Regiões Funcionais de Planejamento 03, 06 e 09 em valores presentes no período 2003-2010

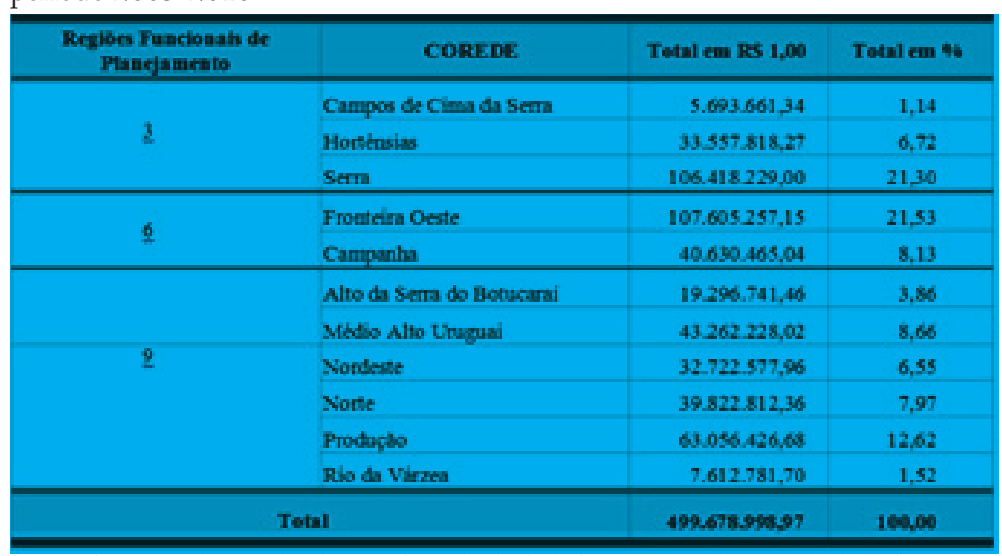

Fonte: Governo do Estado do Rio Grande do Sul. Orçamentos do Estado do RS Período 2003-2010. 
A distribuição dos recursos no período 2003-2010 teve a Região Funcional de Planejamento 09 com 41,18\% dos recursos, seguido da Região Funcional de Planejamento 06 com 29,66\% e a Região Funcional de Planejamento 03 com 29,16\%.

O COREDE que recebeu o maior valor orçamentário foi o COREDE Fronteira Oeste com 21,53\% dos recursos, seguidos pelos COREDE's Serra (21,30\%); Produção (12,62\%); Médio Alto Uruguai (8,66\%); Campanha (8,13\%); Norte (7,97\%); Hortênsias (6,72\%); Nordeste (6,55\%); Alto da Serra do Botucaraí (3,86\%); Rio da Várzea (1,52\%) e Campos de Cima da Serra $(1,14 \%)$.

Os recursos orçamentários atenderam diversas Políticas Públicas de Desenvolvimento Regional geradas em cada um dos COREDE's, durante o período 2003-2010. Conforme visto anteriormente, as Políticas Públicas de Desenvolvimento Regional podem ser classificadas a partir de critérios de falhas de mercado, por meio da aplicação de uma tipologia de Políticas Públicas de Desenvolvimento Regional.

Essa tipologia pode classificar as Políticas Públicas de Desenvolvimento Regional em Política de incentivos à mobilidade de fatores, particularmente de capital de organização (Tipo 1); Políticas de promoção de bem-estar material e imaterial de territórios (Tipo 2); Políticas de mobilização e valorização de capital endógeno (Tipo 3); Políticas de promoção e valorização de externalidades da competitividade empresarial (Tipo 4); Políticas de promoção de competitividade territorial (Tipo 5); Políticas territoriais de aplicação do conceito de estratégias de eficiência coletiva (Tipo 6) e Políticas de robustecimento da espessura institucional (Tipo 7).

A partir da aplicação da tipologia apresentada, com exceção para as Políticas Públicas de Desenvolvimento Regional do Tipo 7, que diferentemente das demais Políticas Públicas de Desenvolvimento Regional, não podem ser observadas pela distribuição de recursos orçamentários por políticas, mas sim pelas práticas e ações de participação empreendidas na construção público-orçamentária e no planejamento e geração de Políticas Públicas de Desenvolvimento Regional de uma determinada região, aspectos que definem a eficiência do desenvolvimento regional decorrentes dos níveis de governança (como direitos) e de capital social (como coesão), como salienta Figueiredo (2009, p.696): 
[...] na dinâmica do longo prazo, baixos níveis de coesão e direitos sistematicamente não assegurados tenderão inevitavelmente a deteriorar as realizações em termos de eficiência. As conseqüências para as Políticas Públicas de Desenvolvimento Regional desta abordagem emergente e ainda não consolidada remete-nos para políticas orientadas para o robustecimento da espessura institucional das regiões. Neste contexto, as Políticas Públicas de Desenvolvimento Regional podem revestir a forma de apoio direto ao quadro institucional, à sua diversidade, à sua sustentação, ao seu apetrechamento técnico.

Assim, o desenvolvimento regional depende da própria qualidade da governança territorial e dos níveis de capital social e de confiança existentes numa dada região ou território.

A participação possibilita a governança e consequentemente o fortalecimento institucional e normativo de geração de Políticas Públicas de Desenvolvimento Regional, em que o resultado da participação amplia os níveis de capital social das regiões e vice-versa, fazendo com que tanto o processo de geração como a execução das Políticas Públicas de Desenvolvimento Regional sejam eficientes no longo prazo, permitindo condições para a consolidação dos objetivos da Constituição Estadual expressos nos artigos 166 a 170.

As políticas de robustecimento e espessura institucional são formadas por ações e normas, que possibilitam que no longo prazo, a coesão social e econômica se desenvolva juntamente com a consolidação de direitos, com o objetivo de garantir a eficiência de políticas que possibilitem o desenvolvimento regional (FIGUEIREDO, 2009), como foi demonstrada na seção anterior pelo Esquema de Mayes (Figura 1).

Assim, as Políticas Públicas de Desenvolvimento Regional que garantem a coesão social e econômica juntamente com a consolidação de direitos, são as próprias ações permanentes de construção de Políticas Públicas de Desenvolvimento Regional promovidas pelos COREDE's e eleitas pela participação dos cidadãos por meio da Consulta Popular.

Segundo Bandeira (apud PRÓ-RS IV, 2010, p.140) a importância da participação da sociedade na promoção do desenvolvimento regional se dá pelos seguintes argumentos:

[...] em primeiro lugar, a participação aumenta a transparência das decisões, reduzindo as oportunidades para a corrupção e para o clientelismo. Em segundo lugar, permite que os programas, projetos e ações se baseiem em um melhor aproveitamento das informações 
disponíveis, aumentando sua eficiência e eficácia. Em terceiro lugar, aumenta a sustentabilidade política das ações, projetos e programas, ao possibilitar sua apropriação pela da sociedade e viabilizar a formação de grupos de interesse que, por meios legítimos, defendam a continuidade da sua implementação. Além disso, a participação estimula a ocorrência de processos de aprendizado coletivo, fortalece os laços comunitários e contribui para acumular o capital social. A participação e o engajamento cívico são elementos essenciais para o bom funcionamento de uma sociedade democrática.

Assim, a participação na construção e escolha de Políticas Públicas de Desenvolvimento Regional, possibilita a consolidação da governança e com ela o fortalecimento do capital social, construídos pelo uso contínuo de instrumentos de participação e de construção de Políticas Públicas de Desenvolvimento Regional.

Mesmo com o diferente comportamento da participação da população no período 2003-2010, a participação tem sido crescente nos diferentes COREDE's, sendo que a partir de 2009, com o comparecimento de mais de 950.000 eleitores em todo o Estado do RS, ficou demonstrada a consolidação da Consulta Popular pela sociedade gaúcha (BANDEIRA apud PRÓ-RS IV, 2010).

$O$ fortalecimento do robustecimento da espessura institucional dos diferentes COREDE's poderá vir com o aumento da participação da sociedade na escolha das Políticas Públicas de Desenvolvimento Regional, em que a maior participação poderá possibilitar a eficiência de escolha de Políticas Públicas de Desenvolvimento Regional que venham a satisfazer o maior número possível de atores socioeconômicos, atingindo assim o desenvolvimento regional em um nível desejado.

Porém, o aumento da participação se dá por meio da geração de capital social, construído por meio de relações de confiança ao longo do tempo, independente dos tipos dessas relações (BANDEIRA apud PRÓ-RS IV, 2010, p.140). Diante desse contexto, surge a possibilidade de consolidação institucional dos COREDE's ao afetar a população regional, como um órgão específico de planejamento e instância de tomada de decisões na construção de Políticas Públicas de Desenvolvimento Regional. Essa consolidação se dá ao longo do tempo, demonstrando que a atuação dos COREDE's tem colaborado na construção de relações que formam os 03 (três) tipos de capital social ("bridging" e "bonding" $e$ "linking"), em que os COREDE's ajudam a criar uma ideia de região, fator básico para o surgimento de uma identidade 
regional, em que antes da sua criação, a noção de que o conjunto de municípios vizinhos, que compunham determinada área, formava uma região (BANDEIRA apud PRÓ-RS IV, 2010).

A partir da diferenciação das políticas do Tipo 7, as regiões utilizando a Consulta Popular como instrumento de participação da população, destinaram seus recursos em valores absolutos no período 2003-2010, para as Políticas Públicas de Desenvolvimento Regional de incentivos à mobilidade de fatores, particularmente de capital de organização (Tipo 1); de promoção de bem-estar material e imaterial de territórios (Tipo 2); de mobilização e valorização de capital endógeno (Tipo 3); de promoção e valorização de externalidades da competitividade empresarial (Tipo 4); de promoção de competitividade territorial (Tipo 5); territoriais de aplicação do conceito de estratégias de eficiência coletiva (Tipo 6), da seguinte forma:

Tabela 2 - Distribuição Orçamentária da Consulta Popular por tipologia de Políticas Públicas de Desenvolvimento Regional no período 2003-2010.

\begin{tabular}{lll}
\hline \hline & & Participação das \\
Tipologias de & \\
$\begin{array}{l}\text { Tipologia de Políticas Públicas de } \\
\text { Desenvolvimento Regional }\end{array}$ & $\begin{array}{l}\text { Valores das Tipolo- } \\
\text { gias em R\$ 1,00 }\end{array}$ & $\begin{array}{l}\text { Políticas Públicas } \\
\text { de Desenvolvi- } \\
\text { mento Regional } \\
\text { em \% }\end{array}$ \\
& &
\end{tabular}

Tipo 1: Política de incentivos à mobilidade de fatores, particularmente de capital de organização

$5.641 .335,90$

Tipo 2: Políticas de promoção de bem- estar material e imaterial de territórios $389.389 .854,28$

77,93

Tipo 3: Políticas de mobilização e valorização de capital endógeno $27.395 .315,84$ 5,48

Tipo 4: Políticas de promoção e valorização de externalidades da competitividade empresarial

$31.372 .400,29$

$$
6,28
$$

Tipo 5: Políticas de promoção de competitividade territorial

39.012.542,19

Tipo 6: Políticas territoriais de aplicação do conceito de estratégias de eficiência coletiva

$6.867 .550,47$

\begin{tabular}{lcc}
\hline Total & $\mathbf{4 9 9 . 6 7 8 . 9 9 8 , 9 7}$ & $\mathbf{1 0 0 , 0 0}$ \\
\hline \hline Fonte: Governo do Estado do Rio Grande do Sul. Orçamentos do Estado do RS - Período 2003-2010.
\end{tabular}

Em termos gerais, as Políticas Públicas de Desenvolvimento Regional de promoção de bem-estar material e imaterial de territórios (Tipo 2), possuíram 77,93\% dos valores destinados à 
Consulta Popular no período 2003-2010, seguidas das Políticas Públicas de Desenvolvimento Regional do Tipo 5, de promoção de competitividade territorial (7,81\%); do Tipo 4, de Políticas de promoção e valorização de externalidades da competitividade empresarial (6,28\%); do Tipo 3, de Políticas de mobilização e valorização de capital endógeno (5,48\%); do Tipo 6, de Políticas territoriais de aplicação do conceito de estratégias de eficiência coletiva (1,37\%); e do Tipo 1, de Política de incentivos à mobilidade de fatores, particularmente de capital de organização $(1,13 \%)$.

Diante da classificação das Políticas Públicas, por meio da aplicação da tipologia apresentada, pode-se observar, as Políticas Públicas de Desenvolvimento Regional, que as populações das Regiões Funcionais de Planejamento 03, 06 e 09 e seus respectivos COREDE's, consideraram prioritárias em termos de destinação orçamentária no período 2003-2010, por meio do Quadro 2.

Quadro 2 - Matriz tipológica de Políticas Públicas de Desenvolvimento Regional

\begin{tabular}{|c|c|c|c|c|c|c|c|}
\hline \multirow[b]{2}{*}{$\begin{array}{l}\text { CORE- } \\
\text { DE }\end{array}$} & \multicolumn{7}{|c|}{ Tipologia de Políticas Públicas de Desenvolvimento Regional } \\
\hline & $\begin{array}{l}\text { Tipo 1: } \\
\text { Políticas } \\
\text { de incen- } \\
\text { tivos à } \\
\text { mobilidade } \\
\text { de fatores, } \\
\text { particu- } \\
\text { larmente } \\
\text { de capital } \\
\text { de organi- } \\
\text { zação }\end{array}$ & $\begin{array}{l}\text { Tipo 2: } \\
\text { Políticas de } \\
\text { promoção } \\
\text { de bem- } \\
\text {-estar } \\
\text { material e } \\
\text { imaterial } \\
\text { de territó- } \\
\text { rios }\end{array}$ & $\begin{array}{l}\text { Tipo 3: } \\
\text { Políticas } \\
\text { de mobi- } \\
\text { lização e } \\
\text { valorização } \\
\text { de capital } \\
\text { endógeno }\end{array}$ & $\begin{array}{l}\text { Tipo 4: } \\
\text { Políticas de } \\
\text { promoção e } \\
\text { valorização } \\
\text { de externa- } \\
\text { lidades da } \\
\text { commpeti- } \\
\text { tividade } \\
\text { empresarial }\end{array}$ & $\begin{array}{l}\text { Tipo 5: } \\
\text { Políticas de } \\
\text { promoção } \\
\text { de } \\
\text { competi- } \\
\text { tividade } \\
\text { territorial }\end{array}$ & $\begin{array}{l}\text { Tipo 6: } \\
\text { Políticas } \\
\text { territoriais } \\
\text { de apli- } \\
\text { cação do } \\
\text { conceito } \\
\text { de estra- } \\
\text { tégias de } \\
\text { eficiência } \\
\text { coletiva }\end{array}$ & $\begin{array}{l}\text { Tipo 7: } \\
\text { Políticas } \\
\text { de } \\
\text { rostec- } \\
\text { mento } \\
\text { da } \\
\text { espessura } \\
\text { institu- } \\
\text { cional }\end{array}$ \\
\hline $\begin{array}{l}\text { Campos } \\
\text { de Cima } \\
\text { da Serra }\end{array}$ & $\mathrm{X}$ & $\begin{array}{l}\text { Regiona- } \\
\text { lização da } \\
\text { saúde }\end{array}$ & $\mathrm{X}$ & $\begin{array}{l}\text { Pólos de } \\
\text { Inovação } \\
\text { Tecnológica }\end{array}$ & $\begin{array}{l}\text { Implan- } \\
\text { tação de } \\
\text { Cursos } \\
\text { Novos na } \\
\text { Rede de } \\
\text { Educação } \\
\text { Profissional }\end{array}$ & $\mathrm{X}$ & $\begin{array}{l}\text { Consulta } \\
\text { Popular e } \\
\text { OREDE's }\end{array}$ \\
\hline $\begin{array}{l}\text { Hortên- } \\
\text { sias }\end{array}$ & $\begin{array}{l}\text { Programas } \\
\text { de Eletrifi- } \\
\text { cação Rural } \\
\text { e Distritos } \\
\text { Industriais }\end{array}$ & $\begin{array}{l}\text { Regiona- } \\
\text { lização da } \\
\text { saúde }\end{array}$ & $\begin{array}{l}\text { Sistema } \\
\text { Integrado } \\
\text { Gestão } \\
\text { Ambiental }\end{array}$ & $\begin{array}{l}\text { Fomento a } \\
\text { Pesquisa e } \\
\text { a Recursos } \\
\text { Humanos }\end{array}$ & $\begin{array}{l}\text { Qualifi- } \\
\text { cando o } \\
\text { Trabalhador } \\
\text { - Quali- } \\
\text { ficação } \\
\text { Profissional } \\
\text { do Traba- } \\
\text { lhador }\end{array}$ & $\begin{array}{l}\text { Redes de } \\
\text { Cooperação } \\
\text { - Parceria } \\
\text { com as } \\
\text { Universi- } \\
\text { dades para } \\
\text { Rede de } \\
\text { Cooperação } \\
\text { Empresarial }\end{array}$ & $\begin{array}{l}\text { Consulta } \\
\text { Popular e } \\
\text { COREDE's }\end{array}$ \\
\hline Serra & $\begin{array}{l}\text { Curso } \\
\text { Capacitação } \\
\text { de Gestores } \\
\text { Municipais } \\
\text { para Planos } \\
\text { Diretores }\end{array}$ & $\begin{array}{l}\text { Região } \\
\text { Resolve }\end{array}$ & $\begin{array}{l}\text { Sistema } \\
\text { Integrado } \\
\text { Gestão } \\
\text { Ambiental }\end{array}$ & $\begin{array}{l}\text { Pólos de } \\
\text { Inovação } \\
\text { Tecnológica }\end{array}$ & $\begin{array}{l}\text { Qualifi- } \\
\text { cando o } \\
\text { Trabalhador } \\
\text { - Quali- } \\
\text { ficação } \\
\text { Profissional } \\
\text { do Traba- } \\
\text { lhador }\end{array}$ & $\begin{array}{l}\text { Extensão } \\
\text { Empresarial }\end{array}$ & $\begin{array}{l}\text { Consulta } \\
\text { Popular e } \\
\text { COREDE's }\end{array}$ \\
\hline $\begin{array}{l}\text { Campa- } \\
\text { nha }\end{array}$ & $\mathrm{X}$ & $\begin{array}{l}\text { Regiona- } \\
\text { lização da } \\
\text { saúde }\end{array}$ & $\begin{array}{l}\text { Recu- } \\
\text { peração } \\
\text { de Áreas } \\
\text { Degradadas }\end{array}$ & $\begin{array}{l}\text { Fomento a } \\
\text { Pesquisa e } \\
\text { a Recursos } \\
\text { Humanos }\end{array}$ & $\begin{array}{l}\text { Inserção do } \\
\text { Jovem no } \\
\text { Mercado } \\
\text { Formal de } \\
\text { Trabalho }\end{array}$ & $\begin{array}{l}\text { Extensão } \\
\text { Empresarial }\end{array}$ & $\begin{array}{l}\text { Consulta } \\
\text { Popular e } \\
\text { COREDE's }\end{array}$ \\
\hline
\end{tabular}




\begin{tabular}{|c|c|c|c|c|c|c|c|}
\hline \multirow[b]{2}{*}{$\begin{array}{l}\text { CORE- } \\
\text { DE }\end{array}$} & \multicolumn{7}{|c|}{ Tipologia de Políticas Públicas de Desenvolvimento Regional } \\
\hline & $\begin{array}{l}\text { Tipo 1: } \\
\text { Políticas } \\
\text { de incen- } \\
\text { tivos à } \\
\text { mobilidade } \\
\text { de fatores, } \\
\text { particu- } \\
\text { larmente } \\
\text { de capital } \\
\text { de organi- } \\
\text { zação }\end{array}$ & $\begin{array}{l}\text { Tipo 2: } \\
\text { Políticas de } \\
\text { promoção } \\
\text { de bem- } \\
\text {-estar } \\
\text { material e } \\
\text { imaterial } \\
\text { de territó- } \\
\text { rios }\end{array}$ & $\begin{array}{l}\text { Tipo 3: } \\
\text { Políticas } \\
\text { de mobi- } \\
\text { lização e } \\
\text { valorização } \\
\text { de capital } \\
\text { endógeno }\end{array}$ & $\begin{array}{l}\text { Tipo 4: } \\
\text { Políticas de } \\
\text { promoção e } \\
\text { valorização } \\
\text { de externa- } \\
\text { lidades da } \\
\text { commpeti- } \\
\text { tividade } \\
\text { empresarial }\end{array}$ & $\begin{array}{l}\text { Tipo 5: } \\
\text { Políticas de } \\
\text { promoção } \\
\text { de } \\
\text { competi- } \\
\text { tividade } \\
\text { territorial }\end{array}$ & $\begin{array}{l}\text { Tipo 6: } \\
\text { Políticas } \\
\text { territoriais } \\
\text { de apli- } \\
\text { cação do } \\
\text { conceito } \\
\text { de estra- } \\
\text { tégias de } \\
\text { eficiência } \\
\text { coletiva }\end{array}$ & $\begin{array}{l}\text { Tipo 7: } \\
\text { Políticas } \\
\text { de } \\
\text { rostec- } \\
\text { mento } \\
\text { da } \\
\text { espessura } \\
\text { institu- } \\
\text { cional }\end{array}$ \\
\hline $\begin{array}{l}\text { Fronteira } \\
\text { Oeste }\end{array}$ & $\begin{array}{l}\text { Programas } \\
\text { de Eletrifi- } \\
\text { cação Rural } \\
\text { e Distritos } \\
\text { Industriais }\end{array}$ & $\begin{array}{l}\text { Manu- } \\
\text { tenção, } \\
\text { conservação } \\
\text { e ampliação } \\
\text { dos espaços } \\
\text { escolares }\end{array}$ & $\begin{array}{l}\text { Apoio ao } \\
\text { Empreen- } \\
\text { dedorismo }\end{array}$ & $\begin{array}{l}\text { Arranjo } \\
\text { Produtivo } \\
\text { para Leite }\end{array}$ & $\begin{array}{l}\text { Apoio } \\
\text { e Novas } \\
\text { Formas de } \\
\text { Trabalho e } \\
\text { Geração de } \\
\text { Renda }\end{array}$ & $\begin{array}{l}\text { Extensão } \\
\text { Empresarial }\end{array}$ & $\begin{array}{l}\text { Consulta } \\
\text { Popular e } \\
\text { COREDE's }\end{array}$ \\
\hline $\begin{array}{l}\text { Alto da } \\
\text { Serra do } \\
\text { Botucaraí }\end{array}$ & $\begin{array}{l}\text { Curso } \\
\text { Capacitação } \\
\text { Gestores } \\
\text { Municipais } \\
\text { para Planos } \\
\text { Diretores }\end{array}$ & $\begin{array}{l}\text { Melhoria } \\
\text { das vias } \\
\text { de acesso } \\
\text { rurais } \\
\text { :conser- } \\
\text { vação de } \\
\text { estradas } \\
\end{array}$ & $\begin{array}{l}\text { Projetos } \\
\text { Integrados } \\
\text { de Desen- } \\
\text { volvimento } \\
\text { Sustentável }\end{array}$ & $\begin{array}{l}\text { Arranjo } \\
\text { Produtivo } \\
\text { para Leite }\end{array}$ & $\begin{array}{l}\text { Capacitação } \\
\text { Profissional } \\
\text { do Traba- } \\
\text { lhador }\end{array}$ & $\begin{array}{l}\text { Extensão } \\
\text { Empresarial }\end{array}$ & $\begin{array}{l}\text { Consulta } \\
\text { Popular e } \\
\text { COREDE's }\end{array}$ \\
\hline $\begin{array}{l}\text { Médio } \\
\text { Alto } \\
\text { Uruguai }\end{array}$ & $\begin{array}{l}\text { Programas } \\
\text { de Eletrifi- } \\
\text { cação Rural } \\
\text { e Distritos } \\
\text { Industriais }\end{array}$ & \begin{tabular}{|l} 
Material de \\
motome- \\
canização \\
da Brigada \\
Militar \\
$(\mathrm{BM})$ \\
\end{tabular} & $\begin{array}{l}\text { Projetos } \\
\text { Integrados } \\
\text { de Desen- } \\
\text { volvimento } \\
\text { Sustentável }\end{array}$ & $\begin{array}{l}\text { Fomento a } \\
\text { Pesquisa e } \\
\text { a Recursos } \\
\text { Humanos }\end{array}$ & $\begin{array}{l}\text { Inserção do } \\
\text { Jovem no } \\
\text { Mercado } \\
\text { Formal de } \\
\text { Trabalho }\end{array}$ & $\begin{array}{l}\text { Extensão } \\
\text { Empresarial }\end{array}$ & $\begin{array}{l}\text { Consulta } \\
\text { Popular e } \\
\text { COREDE's }\end{array}$ \\
\hline Nordeste & $\begin{array}{c}\text { Programas } \\
\text { de Eletrifi- } \\
\text { cação Rural } \\
\text { e Distritos } \\
\text { Industriais }\end{array}$ & $\begin{array}{c}\text { Manu- } \\
\text { tenção, } \\
\text { conservação } \\
\text { e ampliação } \\
\text { dos espaços } \\
\text { escolares }\end{array}$ & $\begin{array}{c}\text { Projetos } \\
\text { Integrados } \\
\text { de Desen- } \\
\text { volvimento } \\
\text { Sustentável }\end{array}$ & $\begin{array}{c}\text { Assistência } \\
\text { Técnica na } \\
\text { Implan- } \\
\text { tação e } \\
\text { Operacio- } \\
\text { nalização de } \\
\text { Agroindús- } \\
\text { trias }\end{array}$ & $\begin{array}{c}\text { Inserção do } \\
\text { Jovem no } \\
\text { Mercado } \\
\text { Formal de } \\
\text { Trabalho }\end{array}$ & $\begin{array}{c}\text { Extensão } \\
\text { Empresarial }\end{array}$ & $\begin{array}{l}\text { Consulta } \\
\text { Popular e } \\
\text { COREDE's }\end{array}$ \\
\hline Norte & $\begin{array}{c}\text { Curso } \\
\text { Capacitação } \\
\text { de Gestores } \\
\text { Municipais } \\
\text { para Planos } \\
\text { Diretores }\end{array}$ & $\begin{array}{l}\text { Região } \\
\text { resolve }\end{array}$ & $\begin{array}{c}\text { Projetos } \\
\text { Integrados } \\
\text { de Desen- } \\
\text { volvimento } \\
\text { Sustentável }\end{array}$ & $\begin{array}{l}\text { Fomento a } \\
\text { Pesquisa e } \\
\text { a Recursos } \\
\text { Humanos }\end{array}$ & $\begin{array}{c}\text { Ampliação } \\
\text { e Melhorias } \\
\text { Físicas } \\
\text { na Rede } \\
\text { Estadual } \\
\text { Educação } \\
\text { Profissional } \\
\end{array}$ & $\begin{array}{c}\text { Extensão } \\
\text { Empresarial }\end{array}$ & $\begin{array}{l}\text { Consulta } \\
\text { Popular e } \\
\text { COREDE's }\end{array}$ \\
\hline Produção & $\begin{array}{c}\text { Programas } \\
\text { de Eletrifi- } \\
\text { cação Rural } \\
\text { e Distritos } \\
\text { Industriais }\end{array}$ & $\begin{array}{l}\text { Região } \\
\text { resolve }\end{array}$ & $\begin{array}{c}\text { Projetos } \\
\text { Integrados } \\
\text { de Desen- } \\
\text { volvimento } \\
\text { Sustentável }\end{array}$ & $\begin{array}{c}\text { Assistência } \\
\text { Técnica na } \\
\text { Implan- } \\
\text { tação e } \\
\text { Operacio- } \\
\text { nalização de } \\
\text { Agroindús- } \\
\text { trias }\end{array}$ & $\begin{array}{c}\text { Inserção do } \\
\text { Jovem no } \\
\text { Mercado } \\
\text { Formal de } \\
\text { Trabalho }\end{array}$ & $\begin{array}{c}\text { Redes de } \\
\text { Cooperação } \\
\text { - Parceria } \\
\text { com as } \\
\text { Universi- } \\
\text { dades para } \\
\text { Rede de } \\
\text { Cooperaçãoo } \\
\text { Empresarial }\end{array}$ & $\begin{array}{l}\text { Consulta } \\
\text { Popular e } \\
\text { COREDE's }\end{array}$ \\
\hline $\begin{array}{l}\text { Rio da } \\
\text { Várzea }\end{array}$ & $\mathrm{X}$ & $\begin{array}{l}\text { Regiona- } \\
\text { lização da } \\
\text { saúde }\end{array}$ & $\begin{array}{c}\text { Projetos } \\
\text { Integrados } \\
\text { de Desen- } \\
\text { volvimento } \\
\text { Sustentável }\end{array}$ & $\begin{array}{c}\text { Pólos de } \\
\text { Inovação } \\
\text { Tecnológica }\end{array}$ & $\begin{array}{c}\text { Ampliação } \\
\text { e Melhorias } \\
\text { Físicas } \\
\text { na Rede } \\
\text { Estadual } \\
\text { Educação } \\
\text { Profissional }\end{array}$ & $\mathrm{x}$ & $\begin{array}{l}\text { Consulta } \\
\text { Popular e } \\
\text { COREDE's }\end{array}$ \\
\hline
\end{tabular}

Fonte: Governo do Estado do Rio Grande do Sul. Orçamentos Públicos do Estado do Rio Grande do Sul. Período 2003-2010.

A Política de incentivos à mobilidade de fatores, particularmente de capital de organização (Tipo 1) teve como 
política pública predominante, em termos orçamentários, "Programas de Eletrificação Rural e Distritos Industriais", de responsabilidade da Secretaria de Minas, Energia e Comunicações. Essa política tinha como objetivo atender com o fornecimento de energia elétrica consumidores rurais, de forma a contribuir para a universalização do fornecimento de energia elétrica (ORÇAMENTO PÚBLICO DO ESTADO DO RS, 2004).

As Políticas de promoção de bem-estar material e imaterial de territórios (Tipo 2) tiveram como política pública predominante, em termos orçamentários a "Regionalização da Saúde", de responsabilidade da Secretaria Estadual da Saúde. Essa política era diretriz do Sistema Único de Saúde (SUS) e foi considerada pelo governo do Estado do RS como uma prioridade, com descentralização da gestão para os municípios e do atendimento ambulatorial e hospitalar, fortalecendo as Unidades Ambulatoriais e Hospitalares integrantes dos Pólos Regionais, com o intuito de ampliar a capacidade e a regionalização da prestação de serviços de saúde especializada (MENSAGEM DO GOVERNADOR PARA ASSEMBLÉIA LEGISLATIVA DO ESTADO DO RS, 2005).

As Políticas de mobilização e valorização de capital endógeno (Tipo 3) tiveram como política pública predominante, em termos orçamentários os "Projetos Integrados de Desenvolvimento Sustentável", de responsabilidade da Secretaria Estadual da Agricultura, Pecuária e Agronegócio. Essa política tinha como objetivo promover a geração de renda, através de projetos integrados de desenvolvimento sustentável, visando a organização social das comunidades beneficiadas nas regiões demandadas pela Consulta Popular (ORÇAMENTO PÚBLICO DO ESTADO DO RS, 2004).

Já as Políticas de promoção e valorização de externalidades da competitividade empresarial (Tipo 4) tiveram como política pública predominante, em termos orçamentários, o "Fomento a Pesquisa e a Recursos Humanos", de responsabilidade da Fundação de Amparo à Pesquisa do Estado do RS (FAPERGS). Essa política buscava financiar e conceder auxílio, bolsas de estudo técnico-científico a pesquisadores vinculados às instituições de ensino, centros de pesquisa, órgãos públicos e setor empresarial (ORÇAMENTO PÚBLICO DO ESTADO DO RS, 2004).

As Políticas de promoção de competitividade territorial (Tipo 5) tiveram como política pública predominante, em termos 

Trabalho", de responsabilidade da Secretaria Estadual do Trabalho, Cidadania e Assistência Social. A política "Inserção do Jovem no Mercado Formal de Trabalho" buscava estimular financeiramente empresas e cooperativas de trabalho, bem como propriedades do setor rural, entidades sem fins lucrativos, profissionais liberais e /ou autônomos para a contratação de jovens (ORÇAMENTO PÚBLICO DO ESTADO DO RS, 2004).

Finalmente, as Políticas territoriais de aplicação do conceito de estratégias de eficiência coletiva (Tipo 6) tiveram como política pública predominante, em termos orçamentários a "Extensão Empresarial", de responsabilidade da Secretaria Estadual do Desenvolvimento e dos Assuntos Internacionais. Essa política tinha como objetivo estabelecer sistema de resolução de problemas de gestão técnica e tecnológica, a partir da introdução de inovações e produtos e processos produtivos, nas micro, pequenas e médias empresas e instituições voltadas à gestão da inovação, articulando linhas de financiamento e qualificando extensionistas (ORÇAMENTO PÚBLICO DO ESTADO DO RS, 2004).

A matriz tipológica (Quadro 2) demonstrou as diferenças de Políticas Públicas de Desenvolvimento Regional existentes nos diferentes COREDE's analisados, assim como mostra que alguns tipos de Políticas Públicas de Desenvolvimento Regional não foram aplicadas em alguns COREDE's.

Assim, no COREDE Campos de Cima da Serra, a ausência das Políticas Públicas de Desenvolvimento Regional dos Tipos 1, 3 e 6; a ausência das Políticas Públicas de Desenvolvimento Regional dos Tipos 1 e 6 no COREDE Rio da Várzea e a ausência de Políticas Públicas de Desenvolvimento Regional do Tipo 1 no COREDE Campanha, demonstram que esses COREDE's não estão dando as condições necessárias para o desenvolvimento regional. Isso fica claro uma vez que não estão desenvolvendo soluções para superação de efeitos da segmentação de mercados e remoção de obstáculos à livre circulação de fatores (no caso do Tipo 1), assim como para o desenvolvimento endógeno (no caso do Tipo 3) e para ação mista de intervenção no ambiente externo da competitividade das empresas e das economias de rede (no caso do Tipo 6).

Diferentemente desses COREDE's, os COREDE's Hortênsias, Serra, Fronteira Oeste, Alto da Serra do Botucaraí, Médio Alto Uruguai, Nordeste, Norte e Produção, de acordo com a tipologia aplicada, contemplam as condições necessárias de 
desenvolvimento regional, ao completarem as Políticas Públicas de Desenvolvimento Regional da matriz tipológica.

As Políticas Públicas de Desenvolvimento Regional do Tipo 2, de promoção de bem-estar material e imaterial de territórios, concentram principalmente políticas voltadas às áreas de Educação, Saúde e Segurança, podendo ser explicada a grande destinação de recursos para essas Políticas pelo Artigo 169 da Constituição Estadual, que estabelece prioridade em investimentos aos serviços básicos da população.

Também fica demonstrada a necessidade da manutenção e consolidação de: Políticas Públicas de Desenvolvimento Regional do Tipo 7, para o robustecimento da espessura institucional de todos os COREDE's analisados, com o intuito de elevar os níveis de governança e capital social, sensibilizando as populações dessas regiões para o estabelecimento de Políticas Públicas de Desenvolvimento Regional, que ainda não existem e que completam a matriz tipológica; e a manutenção e fortalecimento dos COREDE's que apresentam todas as Políticas Públicas de Desenvolvimento Regional, para que sejam dadas condições de desenvolvimento regional no Estado do RS como propõe a Constituição Estadual.

Assim, diante da construção da matriz tipológica para os COREDE's das Regiões Funcionais de Planejamento 03, 06 e 09, a partir da análise realizada por meio de uma tipologia de Políticas Públicas de Desenvolvimento Regional baseada nas falhas de mercado, observa-se que as Políticas Públicas de Desenvolvimento Regional construídas nos COREDE's Hortênsias, Serra, Fronteira Oeste, Alto da Serra do Botucaraí, Médio Alto Uruguai, Nordeste, Norte e Produção tornam propício o desenvolvimento regional de acordo com a tipologia proposta por Figueiredo (2009), satisfazendo as 07 (sete) tipologias da matriz, atendendo, assim, os critérios de institucionalização de regiões, governança, responsabilização e clareza da restrição orçamentária, de acordo com a Regionalização Administrativa proposta pela Constituição Estadual.

\section{Considerações finais}

Inicialmente, observando-se a matriz tipológica, fica demonstrado que a aplicação da tipologia contribuiu para verificar que as Políticas Públicas podem ser classificadas e 
enquadradas dentro de uma tipologia de Políticas Públicas de Desenvolvimento Regional, nos termos definidos por Figueiredo (2009). Mais do que isto, servem como um instrumento de análise da gestão, execução, coordenação e avaliação de Políticas Públicas de Desenvolvimento Regional, independentemente de valor orçamentário, demanda, execução, frequência ou o período dessas políticas. $\mathrm{O}$ único requisito para que isso aconteça, é que sejam respeitados os critérios de Regionalização Administrativa de institucionalização de regiões, governança, responsabilização e clareza da restrição orçamentária.

Além disso, quando respeitados esses critérios de Regionalização Administrativa, a aplicação da tipologia considera que todas as Políticas Públicas são Políticas Públicas de Desenvolvimento Regional.

Ao se construir a matriz tipológica, observa-se que a construção do desenvolvimento regional está alicerçada num ciclo de Políticas Públicas de Desenvolvimento Regional, em que as políticas do Tipo 1, 2, 3, 4, 5 e 6 dependem das Políticas Públicas de Desenvolvimento Regional do Tipo 7 e que essas dependem daquelas. Ocorrendo falhas num dos tipos, poderá ficar comprometido o desenvolvimento regional em toda a matriz de Políticas Públicas de Desenvolvimento Regional.

No caso do Rio Grande do Sul, observou-se que os COREDE's Hortênsias, Serra, Fronteira Oeste, Alto da Serra do Botucaraí, Médio Alto Uruguai, Nordeste, Norte e Produção, de acordo com a tipologia aplicada, contemplam as condições necessárias de desenvolvimento regional, ao completarem as Políticas Públicas de Desenvolvimento Regional da matriz tipológica. Entretanto, em três outros COREDE's isto não se verifica.

O COREDE Campos de Cima da Serra evidenciou a ausência das Políticas Públicas de Desenvolvimento Regional dos Tipos 1, 3 e 6. A ausência das Políticas Públicas de Desenvolvimento Regional dos Tipos 1 e 6 foi observada no COREDE Rio da Várzea. Já no COREDE Campanha, foram as Políticas Públicas de Desenvolvimento Regional do Tipo 1 que não foram identificadas. À luz da tipologia utilizada, pode-se dizer que, no que tange às políticas públicas, esses COREDE's não estão oferecendo as condições necessárias para o desenvolvimento regional. 
Isso fica claro uma vez que não estão desenvolvendo soluções para superação de efeitos da segmentação de mercados e remoção de obstáculos à livre circulação de fatores (políticas do Tipo 1), nem para o desenvolvimento endógeno (políticas do Tipo 3) e nem para ação mista de intervenção no ambiente externo da competitividade das empresas e das economias de rede (Tipo 6).

Neste cenário, o uso da tipologia proposta por Figueiredo (2009) pode ser utilizada pela gestão pública, pois possibilita uma análise panorâmica do arcabouço de políticas de desenvolvimento regional que seriam necessárias para conduzir ao desenvolvimento. Ou seja, respeitados critérios políticos, sociais e econômicos como a institucionalização de regiões, estágios de governança, responsabilização e clareza da restrição orçamentária, uma matriz tipológica completa, sinalizaria para um potencial desenvolvimento regional.

\section{Referências}

ASSEMBLÉIA LEGISLATIVA DO RIO GRANDE DO SUL. Lei 10.283 de 17 de outubro de 1994. Disponível em: <http://www.al.rs.gov. br/legis>. Acesso em: 20 jun. 2011.

. Constituição do Estado do Rio Grande do Sul de 1989. Disponível em: <http://www.al.rs.gov.br/prop/Legislacao/Constituicao>. Acesso em: 20 jun. 2011.

BANDEIRA, Pedro Silveira. Desequilíbrios Regionais - Crescimento Regional no Rio Grande do Sul: Tendências e Desafios - RS2010. Porto Alegre. SCP. 1998

Participação, Articulação de Atores Sociais e Desenvolvimento Regional. Texto para Discussão no 630. IPEA. Brasília, fevereiro de 1999.

.O Capital Social e a atuação dos Conselhos Regionais de Desenvolvimento no Rio Grande do Sul. Tese (Doutorado em Ciência Política) - Programa de Pós-Graduação em Ciência Política da Universidade Federal do Rio Grande do Sul. Porto Alegre, 2003. 365 p.

.Uma Experiência de lnstitucionalização de Regióes no Brasil: Os COREDE's do Rio Grande do Sul. Porto Alegre: UFRGS, 2004.

BRESSER-PEREIRA, Luiz Carlos. Crise Econômica e Reforma do Estado no Brasil: Para uma nova interpretação da América Latina. São Paulo: Nobel, 1996. 
BRESSER-PEREIRA. Descentralização Geográfica e Regional: Brasil e Europa. In: Seminário Internacional sobre Descentralização nos Membros da União Européia e na América Latina, patrocinado pela Escola Galega de Administração Pública e o Instituto Europeu de Administração Pública de Maastricht, Compostela, 2000.

DE LIMA, Mário Jaime Gomes. A dívida pública do Rio Grande do Sul: Origens de sua formação e perspectiva de futuros impactos. Período 1990-2006. 2006. 164 f.Monografia (Bacharelado em Ciências Econômicas) - Faculdade de Ciências Econômicas do Centro Universitário La Salle. Canoas. Disponível em: http://www.al.rs.gov.br/Com/ divida_publica_RS.pdf. Acesso em: 04 out. 2010.

DYE, Thomas D. Understanding public policy. Englewood Cliffs: Prentice- Hall, 1984.

EASTONE, David. A framework for political analysis. Englewood Cliffs: Prentice Hall, 1965.

EVANS, Peter. Predatory, developmental, and other apparatuses: a comparative political economy perspective on the third world state. Sociological Forum. V. 4. No 4, 1989.

FIGUEIREDO, Antonio Manuel. As políticas e o planeamento do desenvolvimento regional. IN: COSTA, José da Silva; NIJKAMP, Peter (Org.). Compêndio de Economia Regional: Teoria, Temáticas e Políticas. v. 1. Coimbra: Principia, 2009.

FÓRUM DOS CONSELHOS REGIONAIS DE DESENVOLVIMENTO DO ESTADO DO RIO GRANDE DO SUL. PRÓ-RS IV: Propostas estratégicas para o desenvolvimento regional do Estado do Rio Grande do Sul (2011-2014). Passo Fundo: Passografic, 2010.

GOVERNO DO ESTADO DO RIO GRANDE DO SUL. Orçamento Público do Estado do Rio Grande do Sul 1998. Secretaria Estadual de Planejamento, Gestão e Participação Cidadã. 1998. Disponível em: http://www.seplag.rs.gov.br/. Acesso em: 08 mar. 2011.

Orçamento Público do Estado do Rio Grande do Sul 1999. Secretaria Estadual de Planejamento, Gestão e Participação Cidadã. 1999. Disponível em: http://www.seplag.rs.gov.br/. Acesso em: 08 mar. 2011.

Orçamento Público do Estado do Rio Grande do Sul 2000.

Secretaria Estadual de Planejamento, Gestão e Participação Cidadã.2000. Disponível em: http://www.seplag.rs.gov.br/. Acesso em: 10 mar. 2011. 
GOVERNO DO ESTADO DO RIO GRANDE DO SUL. Orçamento Público do Estado do Rio Grande do Sul 2001. Secretaria Estadual de Planejamento, Gestão e Participação Cidadã.2001. Disponível em: http://www.seplag.rs.gov.br/. Acesso em: 10 mar. 2011.

Orçamento Público do Estado do Rio Grande do Sul 2002. Secretaria Estadual de Planejamento, Gestão e Participação Cidadã.2004. Disponível em: http://www.seplag.rs.gov.br/. Acesso em: 10 mar. 2011.

Orçamento Público do Estado do Rio Grande do Sul 2003. Secretaria Estadual de Planejamento, Gestão e Participação Cidadã.2003. Disponível em: http://www.seplag.rs.gov.br/. Acesso em: 10 mar. 2011.

Orçamento Público do Estado do Rio Grande do Sul 2004. Secretaria Estadual de Planejamento, Gestão e Participação Cidadã.2004. Disponível em: http://www.seplag.rs.gov.br/. Acesso em: 10 mar. 2011.

Orçamento Público do Estado do Rio Grande do Sul 2005. Secretaria Estadual de Planejamento, Gestão e Participação Cidadã.2005. Disponível em: http://www.seplag.rs.gov.br/. Acesso em: 15 mar. 2011.

Orçamento Público do Estado do Rio Grande do Sul 2006. Secretaria Estadual de Planejamento, Gestão e Participação Cidadã.2006. Disponível em: http://www.seplag.rs.gov.br/. Acesso em: 20 mar. 2011.

Orçamento Público do Estado do Rio Grande do Sul 2007. Secretaria Estadual de Planejamento, Gestão e Participação Cidadã.2007. Disponível em: http://www.seplag.rs.gov.br/. Acesso em: 04 abr. 2011.

Orçamento Público do Estado do Rio Grande do Sul 2008. Secretaria Estadual de Planejamento, Gestão e Participação Cidadã.2008. Disponível em: http://www.seplag.rs.gov.br/. Acesso em: 18 abr. 2011.

Orçamento Público do Estado do Rio Grande do Sul 2009. Secretaria Estadual de Planejamento, Gestão e Participação Cidadã.2009. Disponível em: http://www.seplag.rs.gov.br/. Acesso em: 19 abr. 2011. 
GOVERNO DO ESTADO DO RIO GRANDE DO SUL. Orçamento Público do Estado do Rio Grande do Sul 2010. Secretaria Estadual de Planejamento, Gestão e Participação Cidadã.2010. Disponível em: http://www.seplag.rs.gov.br/. Acesso em: 22 abr. 2011.

Orçamento Público do Estado do Rio Grande do Sul 2011. Secretaria Estadual de Planejamento, Gestão e Participação Cidadã.2011. Disponível em: http://www.seplag.rs.gov.br/. Acesso em: 05 mai. 2011.

. Índice de Desenvolvimento Socioeconômico (IDESE). Fundação de Economia e Estatística do Estado do Rio Grande do Sul. Disponível em http://www.fee.tche.br/sitefee/pt/content/estatisticas/pg idese.php. Acesso em: 25 jul. 2011.

KRUTZMANN, Vanessa; MASSUQUETTI, Angélica. O Processo de constituição dos Conselhos Regionais de Desenvolvimento Econômico do Rio Grande do Sul: Análise da Evolução do Padrão de Vida da População no Período 2000-2004. In: II ENCONTRO DE ECONOMIA CATARINENSE DE ARTIGOS CIENTÍFICOS, TEMÁTICA DESENVOLVIMENTO REGIONAL, 2008, Chapecó. p. 372-397.

LASWELL, Harald .D. Politics: Who Gets What, When, How. Cleveland: Meridian Books, 1936.

LINDBLOM, Charles E. The Science of Muddling Through. Public Administration Review, Yale, v.19, n.19, 1959, p. 78-88.

LYNN, Lawrence E.; GOULD, Stephanie G. Designing Public Policy: A Casebook on the Role of Policy Analysis. Santa Monica: Goodyear, 1980.

MEAD, Lawrence M. Public Policy: Vision, Potential, Limits. Policy Currents, Washington, v.16, n.5, p. 1-4, fevereiro.1995.

PETERS, Guy B. American public policy: Promise and performance. 2.ed. Chatham: Chatham House, 1986.

PONTIFÍCIA UNIVERSIDADE CATÓLICA DO RIO GRANDE DO SUL. Modelos: Normas Técnicas de Documentação. Disponível em: http://www3.pucrs.br/portal/page/portal/biblioteca/Capa/ BCEPesquisa/BCEPesquisaModelos. Acesso em:10 ago. 2011.

PUTNAM, Robert D. Comunidade e Democracia: A experiência da Itália moderna. 5. ed. Rio de Janeiro: FGV, 2005. 
SCARTH, William M. Macroeconomics: an introduction to advanced methods. Ann Arbor: Harcourt Brace Jovanovich, 1988.

SECRETARIA DO ESTADO DE PLANEJAMENTO, GESTÃO, CONTROLE E PARTICIPAÇÃO CIDADÃ. Rumos 2015. Disponível em: http://www.seplag.rs.gov.br/rumos2015.asp. Acesso em: 28 jun. 2011.

SIMON, Herbert A. Comportamento Administrativo. Rio de Janeiro: USAID. 1957.

SOUZA, Celina. Políticas Públicas: Uma revisão da literatura. Sociologias, Porto Alegre, ano 8, n. 16, p.20-44. jul./dez. 2006.

TEIXEIRA, Elenaldo Celso. O Papel das Políticas Públicas no Desenvolvimento Local e na Transformação da Realidade. Disponível em: http://www.fit.br/home/link/texto/politicas_publicas.pdf. Acesso em: 06 ago. 2010.

\title{
TYPOLOGY OF PUBLIC POLICIES AS A TOOL FOR MANAGEMENT, IMPLEMENTATION, COORDINATION AND EVALUATION OF REGIONAL DEVELOPMENT: AN APPLICATIONTO THE STATE OF RIO GRANDE DO SUL, BRAZIL
}

\begin{abstract}
The objective of this paper is to analyze the construction of Public Policies for Regional Development in the State of Rio Grande do Sul, in what regard the Conselhos Regionais de Desenvolvimento - COREDE. Particularly, this paper aims to know if those policies gave conditions for regional development as proposed by the State Constitution, assuring the institutionalization of regions, governance, accountability and clarity of the budget constraint. The analysis encompasses the application of the typology of Public Policy for Regional Development proposed by Figueiredo (2009) within three Functional Regions Planning (RFP) of the State of Rio Grande do Sul, in their respective COREDE: Hortênsias, Serra and Campos de Cima da Serra (RFP 3); Campanha and Fronteira Oeste (RFP 6); Alto da Serra do Botucaraí, Médio Alto Uruguai, Nordeste, Norte, Produção and Rio da Várzea (RFP 9).
\end{abstract}

Keywords: Public Policy. Regional Development. Administrative Regionalization. 